\title{
Contribuições da didática e da técnica da discussão para o ensino do Direito
}

\author{
Larissa Tenfen Silva* \\ Claudio Ladeira de Oliveira**
}

\section{DIDÁTICA NO ENSINO SUPERIOR E CONTRIBUIÇÕES AO ENSINO DO DIREITO}

O ensino do Direito no Brasil vem, ao longo dos últimos anos, sendo alvo de diversas reflexões e reformulações, buscando assim repostas para as suas ineficiências, diante do um ensino tradicionalmente vinculado a concepções elitistas, dogmáticas, acrítico e dissociadas da realidade social, bem como desvinculados de preocupações mais técnicas no tocante ao processo de ensino aprendizagem, motivo pelo qual ainda se caracteriza com um modelo de "ensino bancário" no qual o aluno é tido como um mero depositário dos conteúdos repassados pelos docentes através das aulas dispositivas (aula conferência). ${ }^{1}$

Em sendo o Direito uma área específica de produção e repasse de conhecimento, faz-se cada vez mais necessário refletir sobre as formas nas quais os professores podem estimular a reflexão, produção e compreensão do Direito, bem como a sua própria atuação profissional, buscando assim, meios para a melhor qualidade de ensino jurídico. É com este intuito que se busca a vinculação com a área da Didática e da Pedagogia.

O processo de formação dos professores do ensino superior, diferente do que ocorre com os professores do ensino fundamental e médio que passam por um processo de formação pedagógica árduo desenvolvido nos cursos de Licenciatura, não apresentam uma formação pedagógica de forma tão específica e aprofundada, ainda, que muitos possuam títulos de mestres ou doutores.

\footnotetext{
* Mestre em Direito pela UFSC. Professora do Curso de Direito da Faculdade CESUSC mantida pelo Complexo de Ensino Superior de Santa Catarina.

** Doutor em Direito pela UFSC. Professor adjunto da Faculdade de Direito da Universidade Federal de Santa Catarina (UFSC).
} 
Conforme explica Antônio Carlos Gil, uma das principais justificativas é o fato do professor universitário lidar com adultos enquanto só professores do ensino médio e fundamental lidam com crianças e adolescentes, sendo o tradicional entendimento que somente estes é que necessitam de auxílio pedagógico.

Para o autor, outros motivos justificam essa situação, tal como a própria compreensão da palavra pedagogia que enfoca o sentido de estudo voltado para conduzir crianças e adolescentes. Além disso, os estudantes universitários, por já possuírem uma personalidade formada e por saberem o que pretendem, não exigem de seus professores mais do que competência para transmitir os conhecimentos e para sanar suas dúvidas. O que importa para o professor do ensino superior é ter domínio dos conhecimentos referentes à matéria que leciona aliado sempre que possível, à prática profissional. Seus alunos, por serem adultos e por terem interesses profissionais, estariam suficientemente motivados para a aprendizagem e não apresentariam problemas de disciplina como em outros níveis de ensino. Esta foi ou é ainda um dos mais significantes motivos pela pouca preocupação das autoridades educacionais com a preparação de professores para o ensino superior, já que estes deveriam ter suas atividades e preocupações mais voltadas para pesquisa.

Todavia, tal situação começou a mudar, em especial com a expansão do ensino superior quando um maior número de pessoas chegou à universidade, quando os cursos se tornam mais específicos e que o controle sobre a qualidade do ensino e a capacitação dos docentes decaiu. Todos estes fatores, somados a uma visão mais crítica do ensino, conduzem a identificação da necessidade de o professor universitário se dotar de conhecimentos e habilidades de natureza pedagógica. E isto fica patente na própria fala dos estudantes que reconhecem a competência técnica dos professores, mas criticam suas competências didáticas. ${ }^{2}$

E esta é uma situação que também atingiu e, ainda hoje atinge, a área do Direito, diante da existência de docentes pouco ou totalmente despreparados no estudo de práticas didáticas, seja pelo motivo de serem apenas professores graduados ou especialistas que nunca cursaram tais disciplinas e acabaram por aprender na prática, a ser professor; ou por serem professores que cursaram mestrados ou doutorados que não tinham incluídos nos currículos tais disciplinas.

Claro que aqui temos que fazer uma importante ressalva, isto porque nem todo professor graduado ou especialista ou que seja um profissional da área técnica, tipo juiz, promotor, etc, que não tenha cursado tais disciplinas, não tenham grande capacidades didáticas. Até porque todos estes foram alunos e têm alguma noção de como é uma boa aula, além do fato de procuraram sozinhos suprir suas carências com estudo autodidata. Assim como também não significa que professores que cursaram tais disciplinas de fato saibam repassar a matéria de uma disciplina de forma clara. Mas, a probabilidade passa a ser muito maior neste último caso, principalmente pela compreensão das relações entre educação, 
ensino e didática estarem muito mais claras e a partir daí serem traduzidas em estratégias práticas aliadas com os conteúdos.

Desta forma, tem que se ter muito presente a necessidade de utilizar os pressupostos do conhecimento da área da Pedagogia e da Didática na área do Direito, já que o ensino superior de Direito é essencialmente atividade de ensino. Tal como esclarece Deisy Ventura: "o profissional que forma o profissional em Direito não é, portanto, quando no âmbito da IES, um profissional do Direito, mas sim um profissional da educação."

Nesse sentido, a Pedagogia é reconhecida como a arte ou ciência da educação voltada tanto para crianças como para adultos. $\mathrm{O}$ estudo etimológico do termo, que tem origem grega nas palavras paidós (criança) e gogein (conduzir) entendem que a pedagogia seria um ensino voltado somente para crianças ou no máximo para adolescentes. Por isso alguns autores preferem o uso do termo Androgogia, do grego andragos (adulto), para se referir a educação à formação adulta. Todavia, tal distinção é desnecessária, pois hoje se entende o termo pedagogia de maneira ampla que enfoca tanto criança como adulto, ainda que tradicionalmente a maioria dos estudos e ações práticas tem sido dirigida para as crianças. ${ }^{4}$ A Pedagogia assim está voltada ao tema amplo da educação.

Relacionada ao termo pedagogia, está o termo didática. Didática deriva da palavra grega didaktiké que significa arte de ensinar. Hoje, apesar da existência de várias definições diferentes, o sentido mais utilizado é aquele que a entende como ciência, técnica ou arte de ensinar, ou seja, de ajudar alguém a adquirir conhecimento. ${ }^{5}$

Assim, se a finalidade do profissional do magistério é o ensino, a didática ocupa um lugar especial neste processo já que suas finalidades, modos e condições visam possibilitar o ensino dentro dos parâmetros socialmente estabelecidos do que venha a ser educação.

Como explica Libâneo, a Didática é a disciplina que estuda o processo de ensino tomado em seu conjunto, isto é, os objetivos educativos e os objetivos de ensino, os conteúdos científicos, os métodos e as formas de organização do ensino, as condições e meios que mobilizam o aluno para o estudo ativo e seu desenvolvimento intelectual; e para isso investiga as leis e princípios gerais do ensino e da aprendizagem, conforme as condições concretas em que se desenvolvem. Assim, ela investiga os fundamentos, condições e modos de realização da instrução e do ensino. Trata-se de uma teoria geral do ensino. ${ }^{6}$

Para fornecer os instrumentos para efetivação dos pressupostos didáticos, existem métodos e técnicas. Conforme Imídeo G. Nerici, em termos gerais, podese diferenciar método e técnica de ensino. Os métodos de ensino ou métodos didáticos são a ordenação lógica e entrosada de todas as atividades a realizar em uma tarefa educativa, ou seja, é a coordenação unitária das diversas técnicas para efetivação do ensino, ao passo que a técnica é o recurso particular de que se 
lança mão para a efetivação dos propósitos do método. A diferença entre ambos muitas vezes é questão de amplitude. Uma técnica pode ser considerada método se utilizada de maneira sistemática para efetuar todo o estudo de uma unidade ou tema, mas continua sendo técnica se utilizada dentro de um conjunto maior em que representa um momento no estudo sistemático de uma unidade ou tema. ${ }^{7}$

É importante ficar claro que a Didática é essencial para instrumentalizar o processo de ensino pelos professores e de aprendizagem dos alunos, concretizando os fundamentos da educação. E para isto é essencial a compreensão da questão do processo de ensino-aprendizagem, até porque uma das principais questões relacionadas à atuação do professor universitário se refere ao modo de como o profissional compreende a relação entre ensino e aprendizagem, ou seja, se o professor no desenvolver de suas atividades coloca ênfase no ensino ou na aprendizagem, sendo que sua opção por uma ou outra indica seu modelo de atuação, ainda quando feita de forma inconsciente.

A relação entre ensino e aprendizagem não é uma relação mecânica de simples transmissão do professor que ensina para um aluno que aprende, mas é sim uma relação recíproca na qual se destacam o papel dirigente do professor e a atividade dos alunos. ${ }^{8}$

Em termos gerais, o ensino tem o objetivo de assegurar a difusão e o domínio dos conhecimentos sistematizados legados pela humanidade, sendo uma de suas tarefas básicas a seleção e organização do conteúdo de ensino e dos métodos apropriados. Neste caminho, o ensino visa estimular, dirigir, incentivar, impulsionar o processo de aprendizagem dos alunos, tendo caráter pedagógico, ou seja, de dar um rumo definido para o processo educacional que se realiza na escola.

Já a aprendizagem está mais voltada à assimilação ativa de conhecimentos e de suas operações mentais, visando à compreensão e aplicação consciente e autônoma dos conhecimentos pelos alunos. A aprendizagem é uma forma de conhecimento humano - relação cognitiva entre aluno e matéria de estudo desenvolvendo-se sob as condições específicas do processo de ensino. O ensino não existe por si mesmo, mas na relação com a aprendizagem.

Conforme explica Libâneo, a unidade entre elas fica comprometida quando o ensino se caracteriza pela memorização, quando o professor concentra na sua pessoa a exposição da matéria, quando não suscita o envolvimento ativo dos alunos. Por outro lado, também se quebra a unidade quando os alunos são deixados sozinhos, com o pretexto de que o professor somente deve facilitar a aprendizagem e não ensinar. $\mathrm{O}$ processo de ensino "[...] deve estabelecer exigências e expectativas que os alunos possam cumprir e com isso mobilizem suas energias."

Desta forma, os conceitos de ensino e aprendizagem encontram-se indissociavelmente ligados, "são facetas de um mesmo processo."10 Todavia, 
podem-se fazer algumas diferenciações que ficam estabelecidas, de forma mais exagerada, nos modelos de paradigmáticos de ensino e aprendizagem.

No modelo com ênfase no ensino, os professores colocam seu empenho no ato de ensinar; vêem como fornecedores de informação e como os principais responsáveis pelos resultados obtidos. O processo fica muito centrado no professor, em sua pessoa, qualidades e habilidades. Acredita-se que se o professor ensinou (explicou ou demonstrou) o aluno aprendeu. Tais professores são especialistas em determinadas matérias e cuidam para que sejam conhecidas dos alunos. Sua arte é a da exposição. Os discentes recebem informações que são fornecidas coletivamente demonstrando receptividade e assimilação por meio do dever, da tarefa, do trabalho ou da prova. As preocupações básicas destes professores estão relacionadas com os programas a seguir; as matérias a serem lecionadas; os critérios de aprovação ou reprovação de alunos; por exemplo. Ademais, os conceitos de instrução, orientação, comunicação e transmissão de conhecimentos indicam o direcionamento dos professores. $\mathrm{E}$ a adoção destes pressupostos representa os princípios da Escola Clássica. ${ }^{11}$

Já o modelo centrado na aprendizagem está voltado para os alunos, suas aptidões, expectativas, interesses, oportunidades, possibilidades e condições de aprender. Os alunos são incentivados a expressar suas próprias ideias, a investigar os objetos sozinhos e a procurar os meios para o seu desenvolvimento individual e social. Aqui o professor deixa seu principal papel que é o de ensinar um pouco de lado para ajudar o aluno a aprender, para incentivar a criação de ideias e não apenas introduzi-las; de não fazer preleções para divulgação da cultura, mas organizar estratégias para que o aluno conheça a cultura existente e crie cultura, entre outros. As preocupações do professor passam por questões do tipo quais as expectativas dos alunos; em que medida determinado aprendizado será significativo, que estratégias serão mais adequadas para facilitar o aprendizado, refletindo assim, uma opção por teorias mais humanistas que visam a educação para mudança. Neste modelo, destacam-se os conceitos de descoberta, apreensão, modificação de comportamento e aquisição de conhecimentos que se referem diretamente ao aluno. ${ }^{12}$

Dentro destes dois modelos paradigmáticos existem uma variedade de vertentes teóricas que vem refletindo sobre tal processo ora dando ênfase ao ensino e ora a aprendizagem surgindo inclusive posturas conciliatórias, tal como refletida nas teorias pedagógicas contemporâneas. O ponto é que tais modelos vêm acarretando, no debate sobre a educação no ensino superior, o surgimento de novos conceitos e novos métodos no exercício do magistério, em especial, de modelos que acabam por enfatizar, com maior ou menor medida, aspectos da teoria da aprendizagem na qual o estudante, antes visto como sujeito passivo é visto como sujeito ativo e o professor, mais do que transmissão de conhecimento, é um facilitador, devendo educar o aluno para vida em sociedade. 
Nesta relação, mais uma vez, chama-se atenção para o papel da Didática que é justamente de conduzir / mediar esta relação de ensino e aprendizagem, ${ }^{13}$ devendo o professor ter plena consciência do modelo de ensino a adotar, bem como suas técnicas. É nesse sentido, com um viés mais centrado no modelo baseado na aprendizagem, que segue o presente trabalho sobre a discussão.

A discussão, bem como a sua forma de realização através dos trabalhos em grupo, serve como meio de desenvolver um ensino com vistas à realização de uma formação crítica, reflexiva, autônoma, participativa e inclusiva dos alunos na área do Direito, tendência esta que vem sendo enfatizado pelos principais analistas e estudiosos do ensino jurídico ${ }^{14}$ bem como do próprio Ministério da Educação que através da Resolução n. 9 CNE/CES estatuiu as novas diretrizes curriculares dos cursos de Direito. E este instrumental normativo deixa claro quais as características dos cursos de Direito, bem como as habilidades e competências que devem ser desenvolvidas no corpo discente, servindo a discussão e suas técnicas como formas de fomentar vários destes pressupostos dentro de práticas que enfatizam a aprendizagem discente.

Nesse sentido, vide a Resolução citada:

Art. $3^{\circ}$. O curso de graduação em Direito deverá assegurar, no perfil do graduando, sólida formação geral, humanística e axiológica, capacidade de análise, domínio de conceitos e da terminologia jurídica, adequada argumentação, interpretação e valorização dos fenômenos jurídicos e sociais, aliada a uma postura reflexiva e de visão crítica que fomente a capacidade e a aptidão para a aprendizagem autônoma e dinâmica, indispensável ao exercício da Ciência do Direito, da prestação da justiça e do desenvolvimento da cidadania.

Art. $4^{\circ}$. O curso de graduação em Direito deverá possibilitar a formação profissional que revele, pelo menos, as seguintes habilidades e competências: I - leitura, compreensão e elaboração de textos, atos e documentos jurídicos ou normativos, com a devida utilização das normas técnico-jurídicas; II - interpretação e aplicação do Direito; III - pesquisa e utilização da legislação, da jurisprudência, da doutrina e de outras fontes do Direito; IV - adequada atuação técnico-jurídica, em diferentes instâncias, administrativas ou judiciais, com a devida utilização de processos, atos e procedimentos; V - correta utilização da terminologia jurídica ou da Ciência do Direito; VI - utilização de raciocínio jurídico, de argumentação, de persuasão e de reflexão crítica; VII - julgamento e tomada de decisões; e, VIII - domínio de tecnologias e métodos para permanente compreensão e aplicação do Direito. ${ }^{15}$ 


\section{A IMPORTÂNCIA DA DISCUSSÃO NA FORMAÇÃO DISCENTE}

A discussão é uma das técnicas mais reconhecidas como adequadas para utilização no ensino superior já que seus participantes são, em princípio, alunos adultos com condições cognitivas e afetivas suficientes para participação e obtenção dos vários benefícios que delas decorrem.

É um recurso metodológico que pode ser utilizada facilmente sozinha ou em conjunto com outras, por exemplo, com a aula expositiva, tornando esta muito mais interessante e dinâmica, sendo utilizada por vários professores na área do Direito.

O termo discussão passa a ser compreendido como uma técnica pedagógica que tem como objetivo proporcionar o diálogo entre discentes a respeito de conteúdos técnicos, conhecimentos gerais e valores sociais. Importante que esta interação seja democrática, dialogada, que propicie a cooperação entre os alunos e alunos e docentes, que permita a troca e construção de saberes entre os membros de forma harmônica e não de forma disputada pelo mero ato de convencimento de pontos de vistas estanques e ânimos exaltados ao extremo. Claro que dependendo da forma como a discussão ocorre ela pode ser instrumentalizada mediante o debate (forma de discussão disputada/competição), mas que seja somente uma etapa do procedimento.

A técnica da discussão apresenta vários objetivos pedagógicos importantes que podem ser obtidos com o sua utilização. ${ }^{16}$ Um deles é o favorecimento da reflexão acerca de conhecimentos obtidos mediante leitura ou exposição. Os alunos têm a possibilidade de enfocar um mesmo assunto sob diferentes aspectos, comparar, confrontar, ressaltar semelhanças e diferenças entre eles, fazendo-o com certa independência do professor que observa e corrige quando necessário.

Outro objetivo que pode ser alcançado é oportunizar aos alunos a formulação de princípios com suas próprias palavras reconstruindo as ideias ensinadas, decompondo-as, levando em conta os conhecimentos anteriores, chegando mesmo a formular princípios de maneira própria com suas palavras.

Ademais, pode ajudar aos estudantes a se tornarem conscientes de problemas apresentados em leituras e preleções. A discussão pode fazer com que um mesmo fato seja visto sob muitos aspectos, favorecendo a identificação de problemas que passariam despercebidos numa aula expositiva ou numa simples leitura.

A facilitação de aceitação de informações ou de teorias contrárias às crenças tradicionais ou ideias prévias é outro objetivo a ser concretizado. A discussão passa a ser a estratégia mais adequada para demonstrar aos estudantes quão diferentes podem ser as crenças e valores das pessoas e grupos. É necessário que o professor se disponha a conduzir a discussão com o propósito de promover 
a reflexão acerca do discutido, dos diferentes pontos de vista e que aproveite o momento para enfatizar o papel do julgamento na construção intelectual. ${ }^{17}$

Outro aspecto importante a ser observado é a possibilidade de ensinar o aluno a pensar. Por meio da discussão, os alunos aprendem a abordar racionalmente um tópico, a monitorar os seus próprios processos de pensamento, a questionar suas pressuposições implícitas, havendo também a estimulação do pensamento reflexivo quando o discente chega a um julgamento ou solução capaz de encerrar um problema, ainda que de forma temporária. Interessante observar que o pensamento é estimulado não só quando os alunos efetivamente participam falando durante as discussões, mas também quando há alunos que apenas ouvem de forma atenta os colegas e professores. ${ }^{18}$

Além disso, a discussão pode ainda promover o envolvimento dos alunos realizando objetivos de cunho afetivo, bem como favorecendo o relacionamento entre professor e aluno. Sobre este último objetivo, é importante o professor não esquecer que a motivação para aprender passa também pelo apreço que o aluno sente que o professor tem por ele, bem como pela valorização de suas ideias e encorajamento de sua participação.

Para Nereci a discussão apresenta ainda outras finalidades como a de ensinar ao estudante as várias modalidades da técnica da discussão; a oportunizar a cooperação e o trabalho em grupo; a ampliação de conhecimentos e estudo de novas unidades pelo aluno; a possibilidade do professor dirimir as eventuais dúvidas dos alunos sobre temas já estudados, bem como a fixação e integração de aprendizagens anteriores. ${ }^{19}$

Assim, a discussão se constitui numa técnica baseada na crítica, na compreensão e na cooperação intelectual apresentando como fundamentos a neutralidade quanto aos objetivos a alcançar (pois não existem objetivos de conteúdos preestabelecidos); a pesquisa intelectual; a argumentação objetiva e lógica; a crítica fundamentada e construtiva e o pensamento reflexivo. ${ }^{20}$

Ressalta-se que a escolha pela utilização da técnica em sala de aula demonstra uma forma de suplementação de aulas de caráter somente expositivas ${ }^{21}$ sendo que o professor deve utilizá-la somente quando tiver claro os objetivos que pretenda alcançar, pois ela pode não favorecer, por exemplo, de forma significativa, a obtenção de aprendizagens específicas, tal como a aula expositiva, mas sim a transferência do que já foi aprendido. Assim, o professor deve lembrar que a velocidade de transmissão de novos conhecimentos na discussão é baixa num grupo de discussão.

O professor deve também, tal como menciona Zanou e Althus ${ }^{22}$, ao exigir o uso da discussão, esclarecer seus alunos sobre as expectativas de aprendizagem objetivadas, o que se espera deles no desenvolvimento do seu uso, além de o próprio professor, durante o exercício, ajudar os estudantes propondo 
perguntas, problematizando questões para o debate, e não somente responder o que se deseja. ${ }^{23}$

É importante lembrar que uma discussão mal conduzida costuma ser frustrante tanto para os professores como para os alunos. Longos silêncios, estudantes que se recusam ou temem participar, agressões entre colegas, domínio por parte de um pequeno número de estudantes são situações que podem ocorrer e desestimular o uso da técnica.

As discussões, em salas de aula, podem ser vistas por alguns estudantes como uma oportunidade de exaltação pessoal e cultural. Isso porque os estudantes trazem para a sala de aula não apenas a vontade de aprender, mas vaidades, frustrações, ambições, temores e diferenças. O professor deve então estar atento a tais questões e situações para conduzir de forma democrática e participativa a discussão.

Conforme enfatiza Lowman, a discussão para ser bem sucedida depende de várias qualidades do professor, tal como a espontaneidade, criatividade, tolerância pelo desconhecido, capacidade de comunicação e habilidades pessoais, sendo que por vezes, conduzir uma discussão pode ser mais difícil do que fazer uma preleção de qualidade, podendo inclusive levar o professor a uma situação de exaustão emocional. ${ }^{24}$

É fato que existem muitas barreiras que levam à resistência dos alunos a utilização da discussão sendo importante ultrapassá-las. Uma primeira barreira a ser vencida é a informação insuficiente sobre o assunto discutido. Isto faz com que os alunos tenham dificuldades de sustentar uma discussão, devendo o professor fornecer antecipadamente as informações necessárias sobre o tema ou, no caso de já iniciado o exercício, adiar a discussão para que os mesmos obtenham as informações necessárias.

Uma segunda barreira que pode surgir advém do medo da crítica. Alunos ficam com medo de participar de discussões por medo da crítica dos professore e colegas, cabendo ao professor definir regras para participação, tal como a regra de proibição de qualquer comentário ofensivo em relação às opiniões expressas pelos estudantes na discussão. E estabelecer regras para si para não fazer o mesmo.

Conclusões prematuras dos professores podem ser vistas como mais um exemplo de barreira. É comum o professor dar uma conclusão prematura da discussão sem que os alunos tenham oportunidade de explorar o problema com a adequada profundidade. Convém que o docente desenvolva habilidade para fazer o resumo da discussão no momento adequado.

Por fim, um último exemplo de resistência à discussão é a existência de consenso prematuro por parte dos alunos acerca dos temas tratados. Por vezes, os alunos se preocupam em chegar a um consenso sobre a discussão, mas essa nem sempre é o objetivo. É importante que o professor procure desenvolver a 
sensibilidade dos alunos para pontos de vista divergentes. O conflito pode ser muito útil para que bons resultados sejam alcançados por meio da discussão. ${ }^{25}$

Além desses problemas que podem surgir para atrapalhar o desenvolvimento da técnica existem outros para os quais o professor deve estar atento. ${ }^{26}$ No caso de desinteresse dos alunos pela discussão, o professor deve verificar se o grupo está deixando pendente pontos importantes que porventura ainda não foram discutidos; ou no caso da discussão já estar encerrada, se os alunos estão evitando pontos polêmicos ou se houve desvio da discussão.

Outro problema que surge na discussão é o excesso de emoção não controlada. Discussões de qualidade são geralmente intensas, desde que não haja explosões de raiva. Interessante o professor ficar atento às vozes e faces dos alunos e no caso de qualquer sinal de descontrole reafirmar o controle da situação mudando o foco da discussão ou fazendo com que os alunos consigam se distanciar um pouco da mesma.

Muito freqüente em discussões é a dominação da palavra por certos alunos tirando a oportunidade de outros de participar, tal como já referenciado acima. O professor não deve permitir o monopólio do uso da palavra para preservar a participação mais ampla possível, a moral da classe e a qualidade geral da discussão.

Por fim, por vezes os professores não percebem a existência de estudantes extremamente isolados ou retraídos. Para reconhecer tais alunos, é importante que o docente, mais uma vez, esteja atento à linguagem não verbal expressa pelos alunos durante a discussão. No caso de perceber alguma intenção de participação, pode convidar tais discentes ao diálogo coletivo, pois fato é que estudante silencioso não é sinônimo de estudante não envolvido já que como observadores podem estar atentos e motivados tais como os participantes diretos.

Existem muitas técnicas específicas que podem ser utilizadas para desenvolver a discussão ${ }^{27}$.

Um primeiro conjunto de técnicas existente enfoca atividades com a sala toda. A discussão com a classe toda é muito utilizada nos cursos de graduação sendo vista como alternativa a aula expositiva. Ela acarreta vários benefícios, pois incentiva os alunos a falar em público expressando suas idéias, reflexões, experiências e vivências; estimula os discentes a ouvir uns aos outro; a dialogar; a argumentar e a respeitar opiniões diferentes, deixando claro que experiências coletivas são importantes.

Mas nem sempre tais discussões são bem sucedidas sendo necessário ao professor dominar bem o assunto a ser debatido, preparar previamente os estudantes e ter habilidade de coordenação de discussão.

Ademais, é importante ressaltar alguns outros cuidados necessários para a condução das discussões. Conforme alerta Gil, o professor precisa ter habilidades 
para iniciar as discussões e ganhar adesão dos alunos. Uma forma eficiente para isto é o docente proporcionar aos estudantes uma experiência comum que pode ser feito por meio de preleção, leitura de textos, apresentação de um filme, entre outros. Outra forma bem comum é dar um problema aos alunos e ir anotando as sugestões de respostas dos mesmos no quadro. A elaboração de perguntas é também outra maneira interessante de fornecer uma experiência comum aos alunos, iniciando com perguntas simples de sim ou não para então sofisticá-las, ganhando aos poucos, a adesão na participação. ${ }^{28}$

A criação de estímulos pelo professor é de fundamental importância, pois ajuda na criação de um clima de participação discente podendo o professor tomar algumas medidas como dispor os alunos em círculos ou semicírculos para favorecer o contato visual; cuidar do tempo da discussão; solicitar a participação dos alunos nas áreas que tenham reconhecida competência; chamar os alunos pelo nome; reforçar a participação dos alunos mediante agradecimentos, sorrisos ou sinas de aquiescência; demonstrar respeito pelas opiniões pessoais dos alunos. ${ }^{29}$

Além das técnicas de discussão com a sala toda existe um grande número de modelos de discussão realizada em pequenos grupos usados principalmente quando as classes apresentarem um número grande de alunos, tais como o "grupo do cochicho", a técnica do fracionamento, o painel integrado, a discussão em dupla e a técnica do seminário.

\section{CONCLUSÃO}

A Discussão é um recurso didático que quando combinado com técnicas específicas para seu fomento apresenta grande possibilidade de contribuição na relação de ensino-aprendizagem, podendo ser facilmente aplicadas em contextos de sala de aula, contrapondo-se ao tradicional sistema bancário caracterizador da área jurídica.

A discussão é uma técnica, tal como bem explicitado acima, que busca desenvolver ou aprimorar nos alunos uma série de habilidades, competências e características que contribuem para a formação técnica dos futuros profissionais, bem como para o próprio desenvolvimento pessoal dos alunos. Nesse sentido, a forma escolhida de como trabalhar com a discussão mediante o formato em grupo ajuda a instrumentalizar e oportunizar a realização destes pressupostos.

Uma das principais finalidades do ensino superior é de capacitar tecnicamente os estudantes para o exercício profissional em certa área do conhecimento, mas também de contribuir na formação pessoal e cidadã dos indivíduos atuantes e participantes de certa sociedade. Esta dimensão mais particularizada é importante para contribuição do aprimoramento da personalidade dos alunos que logo passam a ser vistos como profissionais que objetivam a realização pessoal que perpassa pela ascensão social, financeira, 
intelectual, ou seja, alguns pressupostos para melhor transitar e viver nas sociedades atuais. E é justamente destes indivíduos que se espera uma maior compreensão dos contextos em que vivem, das relações políticas, sociais econômicas, internacionais que existem na sociedade, e que passem a agir de forma a contribuir minimamente para a concretização de um país melhor, ou seja, dos fundamentos e objetivos da República Federativa, tal como estabelecido na Constituição Federal de 1988. Afinal, a educação formal está justamente a serviço dos indivíduos e da sociedade.

Para tanto, a forma pela qual as instituições de ensino superior são estruturas e dirigidas por seus mantenedores ou órgãos governamentais devem refletir e permitir a concretização desses deveres constitucionais e das respectivas políticas educacionais nacionais e específicas, como por exemplo, a concretização das diretrizes nacionais de cursos, que no caso do curso do Direito, exige uma formação de qualidade calcada justamente na concretização de valores, princípios, métodos, técnicas que enfatizem um ensino que valoriza a formação técnica, profissional, científica, humanística e cidadã. E para tanto, os professores devem não só ter a consciência desses deveres profissionais buscando a compreensão e aprimoramento técnico e didático para objetivação desses fins.

Nesse sentido são de grande valor as contribuições da Pedagogia e da Didática sendo que a opção pela utilização da técnica da discussão e do ensino em grupo demonstra isto.

Todavia, o professor não pode esquecer que a escolha pelo uso destas estratégias apresenta objetivos e necessidades específicas de aplicação que devem ser levadas em conta, já que existem situações ou contextos que é mais apropriado a escolha de outros recursos existentes, ficando patente que esse não é um método de ensino que possa ser utilizado para ensinar tudo a todos.

Atento a isto, o professor tem a seu alcance um instrumental muito eficaz para contribuir para uma relação de ensino e aprendizagem permeados pelos preceitos de um ensino dinâmico, socializante, reflexivo, crítico, instigante, inclusivo e participativo.

\section{NOTAS}

1 FREIRE, Paulo. Pedagogia da autonomia: saberes necessários à prática educativa. São Paulo: Paz e Terra, 2011.

2 Cf. GIL, Antônio Carlos. Metodologia do ensino superior. 3 ed. São Paulo: Atlas,1997, p. 15 e16. 1997; . Didática do ensino superior. São Paulo: Atlas, 2006, p. 1 e 6.

3 VENTURA, Deisy. Ensinar direito. Barueri, SP: Manole, 2004, p. 16.

4 Cf. GIL, Antônio Carlos. Metodologia do ensino superior. 3 ed. São Paulo: Atlas,1997, p. 16.

5 Cf. Idem, 2006, p. 2.

6 Cf. LIBANEO, José Carlos. Didática. São Paulo: Cortez, 1994, p. 26;52;54.

RDUNO, v. 1, n. 2, Jul - Dez/2018 - pag (150-166) 
7 NERICI, Imideo G. Metodologia do ensino superior. Lisboa, Portugal: Fundo de Cultura, p. 141 e 184. Nesse caminho, também Gil diferencia didática do conceito de Metodologia do Ensino Superior que seria uma disciplina que procura se caracterizar pelo rigor científico envolvendo os procedimentos que devem ser adotados pelo professor para alcançar os seus objetivos que geralmente são identificados com a aprendizagem dos alunos. Tal disciplina ensina os professores como elaborar planos de ensino, formulação de objetivos, seleção de conteúdos, escolha das estratégias de ensino e instrumento de avaliação da aprendizagem. Cf. GIL,1997, p. 22.

8 Cf. LIBANEO, 1994, p.90.

9 Ibidem, p.91.

10 Ibidem, p.81.

11 Cf. GIL,1997, p. 29-30; 2006, p. 6-7. Gil ressalta a crítica feita por Paulo Freire a esta postura: é um tipo de educação bancária na qual se tem o ato de depositar, transferir e transmitir valores e conhecimento, sendo chamada de bancária. Tal modelo acaba propiciando a memorização mecânica dos conteúdos pelos alunos; além de vê-los como recipientes a serem preenchidos pelas informações do educador.

12 Cf. Ibidem, p. 30-3; Ibidem, p. 7-8. Mas tal modelo também é passível de críticas, em especial, pelos exageros na atribuição de peso nas qualidades pessoais de amizade, carinho, compreensão, amor, tolerância e abnegação entre professor e aluno e da exclusão da tarefa de ensinar pelo professor.

13 Cf. LIBANEO, 1994, p. 90-91.

14 Estes são apenas alguns exemplos de autores e obras que tratam de uma análise do ensino do Direito no Brasil: SOBRINHO, José Wilson Ferreira. Metodologia do ensino jurídico e avaliação em direito. Porto Alegre: Fabris, 1997; FILHO, Álvaro Melo. Metodologia do ensino jurídico. 2. ed. Rio de Janeiro:Forense, 1979; RODRIGUES, Horácio Wanderlei (Org.). Ensino jurídico para que(m)? Florianópolis: Fundação Boiteux, 2000; ARRUDA JR, Edmundo Lima de. Ensino jurídico e sociedade: formação, trabalho e ação social. São Paulo: Acadêmica, 1980; MARTINEZ, Sérgio Rodrigo. A evolução do ensino jurídico no Brasil. Disponível em:<www.ensinojuridico.pro.br $>$. Acesso em: 20 jan. 2012.

15 BRASIL (Ministério da Educação). Resolução n. 9 CNE/CES. Brasília, DF, 2004.

16 Cf. GIL,1997, p.77-78; 2006, p.156-159.

17 Nesse sentido, com explica Lowman, discussão personalizada força os estudantes a encontrar a inconsistência entre seus valores sociais (especialmente quando aplicada a exemplos distantes, grandemente simbólicos) e seus comportamentos e interesses pessoais. Provavelmente os estudantes não vão mudar seus valores da noite para o dia, por causa de tal discussão, mas ganharão uma apreciação mais plena dos conceitos estudados e podem tornar-se menos convencidos de sua superioridade moral. LOWMAN, Joseph. Dominando as técnicas de ensino. Trad. Harue Ohara Avritscher. São Paulo: Atlas, 2004, p. 169.

18 Cf. Ibidem, p. 160.

19 Cf. NERICI, 1973, p. 191-192.

20 Cf. Ibidem, p. 191. Como bem enfatiza a autora em questão existe uma diferença entre discussão e debate. A primeira se caracteriza por um trabalho de cooperação intelectual, enquanto a segunda enfatiza a competição intelectual. Numa discussão há o predomínio da atitude de pesquisa e a intenção de ser encontrada a verdade, ao passo que no debate predomina a intenção de convencer, de demonstrar a superioridade de um ponto de vista, de uma tese ou teoria e quase sempre apresenta contornos emocionais mais latentes. Para aprofundamento da técnica de debate ver paginas $194 \mathrm{e}$ 195 da citada obra.

21 Cf. Ibidem, p. 194. 
22 Este comentário se refere especificamente a técnica de seminário, mas é válida também para outras formas de discussão.

23 Cf. ZANON, D. P.; ALTHAUS, M. T. M. Possibilidades didáticas do trabalho com o seminário na aula universitária. In: VIII Encontro de Pesquisa em Educação da Região Sul - ANPEDSUL, 2010, Londrina. Disponível em: <http://www.maiza.com.br/adm/producao/34.pdf $>$. Acesso em: $28 \mathrm{dez}$. 2012, p. 14.

24 LOWMAN, 2004, p. 157-158 e 183.

25 Cf. GIL,1997, p.81-82;___.2006, p.167-168.

26 Cf. LOWMAN, op. cit., p.181-182.

27 Ver capítulo seis da obra aqui citada do Professor Joseph Lowman sobre técnicas gerais de discussão que podem ser utilizadas para melhorar a aplicação e eficácia das técnicas específicas de ensino em grupo.

28 Cf. GIL, 2006, p161.

29 Cf. Ibidem, p.160-166.

\section{Referencias Bibliográficas}

ARRUDA JR, Edmundo Lima de. Ensino jurídico e sociedade: formação, trabalho e ação social. São Paulo: Acadêmica, 1980.

BRASIL (Ministério da Educação). Resolução n. 9 CNE/CES. Brasília, DF, 2004.

FILHO, Álvaro Melo. Metodologia do ensino jurídico. 2. ed. Rio de Janeiro:Forense, 1979.

FREIRE, Paulo. Pedagogia da autonomia: saberes necessários à prática educativa. São Paulo: Paz e Terra, 2011.

GIL, Antônio Carlos. Metodologia do ensino superior. 3 ed. São Paulo: Atlas, 1997.

. Didática do ensino superior. São Paulo: Atlas, 2006.

GODOY, Arilda Schimidt; CUNHA, Maria Alexandra Viegas Cortez da. Ensino em pequenos grupos. In: MOREIRA, Daniel A. (Org). Didática do ensino superior: técnicas e tendências. São Paulo: Pioneira, 2003, p. 83-100.

GUSTIN, Miracy Barbosa de Sousa; PEREIRA, Aline Rose Barbosa. (Re)pensando uma pedagogia da inclusão em cursos de direito. In:CARVALHO, Evandro Menezes de. (Org.; et al). Representações do professor de direito. Curitiba:CRV, 2012, p.11-23.

LIBANEO, José Carlos. Didática. São Paulo: Cortez, 1994.

LOWMAN, Joseph. Dominando as técnicas de ensino. Trad. Harue Ohara Avritscher. São Paulo: Atlas, 2004. 
MARTINEZ, Sérgio Rodrigo. A evolução do ensino jurídico no Brasil. Disponível em: $<$ www.ensinojuridico.pro.br $>$. Acesso em: 20 jan. 2012.

MUCCHIELLI, R. A formação de adultos. São Paulo: Martins Fontes, 1981 apud GODOY, Arilda Schimidt; CUNHA, Maria Alexandra Viegas Cortez da. Ensino em pequenos grupos. In: MOREIRA, Daniel A. (Org). Didática do ensino superior: técnicas e tendências. São Paulo: Pioneira, 2003, p. 173.

NERICI, Imídeo G. Metodologia do ensino superior. Lisboa, Portugal: Fundo de Cultura, p. 141 e 184.

RODRIGUES, Horácio Wanderlei (Org.). Ensino jurídico para que(m)? Florianópolis: Fundação Boiteux, 2000.

SOBRINHO, José Wilson Ferreira. Metodologia do ensino jurídico e avaliação em direito. Porto Alegre: Fabris, 1997.

TURRA, Clódia Maria Godoy et al. Planejamento de ensino e avaliação. 11 ed. Porto Alegre: Sagra Luzzatto, ano 1975.

VENTURA, Deisy. Ensinar direito. Barueri, SP: Manole, 2004.

ZANON, D. P.; ALTHAUS, M. T. M. Possibilidades didáticas do trabalho com o seminário na aula universitária. In: VIII Encontro de Pesquisa em Educação da Região Sul - ANPEDSUL, 2010, Londrina. Disponível em: <http://www.maiza.com.br/adm/ producao/34.pdf >. Acesso em: $28 \mathrm{dez} .2012$. 


\section{Resumo}

O presente artigo tem por objetivo analisar as contribuições da Didática e da técnica de discussão para o ensino do Direito. Para tanto, num primeiro momento será dado destaque a relevância das contribuições da Didática, enquanto ramo da área da Pedagogia, para compreensão e reflexão sobre as relações de ensino e de aprendizagem, cujos atores principais são os alunos e professores. Em seguida serão apontadas várias contribuições que a discussão pode fomentar na relação de ensino-aprendizagem. Desde já fica pontuado que a técnica de discussão quando bem compreendida e conduzida pelos professores de ensino superior, em especial neste caso, nos cursos de Direito, são excelentes instrumentos que não só servem para o desenvolvimento de várias habilidades e competências necessárias aos alunos, tanto em termos profissionais e pessoais, mas que contribuem para uma aula muita mais animada, participativa e instigante, tanto para os alunos, como para os professores, que tem a oportunidade de aprender e lapidar as suas habilidades e sensibilidade profissional.

Palavras-chave: Ensino do direito. Didática. Técnica. 


\title{
CONTRIBUTION OF THE DIDACTIC AND THE TECHNICS OF DISCUSSION FOR THE LEGAL EDUCATION
}

\begin{abstract}
The present article aims to analyze the contributions of the Didactic and the technics of discussion for the legal education. For this, in a first moment will be highlighted the relevance of the contributions of the didactic, as a branch of the Pedagogy, for the comprehension and reflection about the teaching and learning relations, whose main actors are the students and professors. Next will be pointed several contributions that the discussion can foment in the teaching-learning relations. Since now stay pointed that the technic of discussion when well comprehended and conducted by the higher education professors, especially in this case, in the law schools, are excellent instruments that not only serve for the development of several abilities and competences needed to the students, as in professional and personal terms, but that contribute for a class much more fun, participative and thought-provoking, as for the students, as for the professors, that have the opportunity of learn and lapidate it's professional abilities and sensibilities.
\end{abstract}

Keywords: Legal Education. Didactic. Technics.

Recebido em março de 2018. Aprovado em setembro de 2018. 